\title{
BUSINESS REVENUE AND JOB RETENTION DURING COVID-19 CRISIS IN MANUFACTURING SECTOR IN SERBIA
}

\author{
Ivana Marinovic Matovic \\ PUC Parking Service, Nis, Serbia \\ ivana.m.matovic@gmail.com \\ Andjela Lazarevic \\ University of Nis, Faculty of Mechanical Engineering, Nis, Serbia \\ andjela.lazarevic@gmail.com
}

\begin{abstract}
Manufacturing companies in the Republic of Serbia had to react quickly to the changed business conditions during Covid-19 crisis, in order to adjust their businesses, as well as working conditions to the new circumstances. Since most of the employees in these companies cannot work remotely, maintaining production processes was challenged due to the restrictions imposed by the state and decreased demand for their products. New dynamic environment influenced differently various segments of manufacturing companies' businesses, which affected companies' business revenue and number and structure of its employees. This paper investigates the impact of Covid-19 on the manufacturing companies' business revenue, and subsequently their employees and job retention schemes. It further explores the possibilities of effective crisis management in the Republic of Serbia, as well as readiness of manufacturing companies' employees and management to adapt to the new working environment caused by the Covid-19 pandemic, in order to lessen its impact on the companies' performance and profitability.

Keywords: Crisis Management, Business Revenue, Job Retention, Manufacturing Companies, Covid-19 DOI: https://doi.org/10.24818/beman/2021.S.I.2-09
\end{abstract}

\section{INTRODUCTION}

Covid-19 pandemic was an unexpected and surprising event that had a tremendous impact on the world and European economy. Various sectors responded differently to this crisis; however remote working became the new normal for millions of people around the world in their effort and effort of their employers to retain the job positions (Segal, 2021). Unfortunately, not all sectors could use the benefit of remote working. A recent study from the University of Chicago examined and quantified how many jobs can be done from home. A significant variation across sectors was confirmed, with a general conclusion that the jobs that can be performed from home typically pay more than the jobs that cannot be done remotely. Whereas most jobs in corporate management, finance, education and science can be performed at home, very few jobs in agriculture, forestry, retail trade and manufacturing could be 
done remotely (Dingel \& Neiman, 2020). The focus of this paper is on the manufacturing companies, due to their importance for the Serbian economy, as well as unfavorable position due to the fact that their employees cannot do jobs remotely and that manufacturing business activities were significantly reduced during Covid-19 pandemics.

Manufacturing companies represent legal entities whose main activities are related to the production of goods by transforming various resources such as energy, raw materials, pre-processed parts and components into finished products using employees' knowledge and skills, machines and tools. Various divisions of manufacturing companies could be made in accordance to their size (by number of employees, by business revenue etc.), main industry group they belong to, type of manufacturing processes etc. However, in order to understand the position and the development status of Serbian manufacturing sector, it is important to mention that this sector, together with overall Serbian economy, was a subject of various kinds of disruptions for decades. Nineties (90's) brought UN sanctions, wars, breakdown of the federal state Yugoslavia and NATO bombing, and negative manufacturing industry growth rate (China-CEE Institute, 2019). The Serbian economy started transition from socialist to market oriented through privatization of state owned companies, including wide majority of manufacturing industries. Privatization usually led to the interruptions of the production, while more of the privatized companies changed their core business from manufacturing to services. The economic transition was followed by various kind of resistance, since it was difficult to change peoples' way of thinking and behaving, as well as their expectation from their working and living environment they were facing. Finally, after the decades of gradual devastation, through the inflow of the foreign direct investments, the manufacturing sector has started its recovery, followed by the increasing of the technological knowledge and market liberalization. This recovery was relying on the products bearing a low and middle-low technological content, labor and resource intensive, such as metal processing, industries heavily dependent on machine construction, which create low gross value added (Savic et al., 2015).

Despite this fact and a net loss in 2015 , Serbian manufacturing sector achieved a positive result in the period 2016-2019 - the net result in 2017 was a record 1.2 billion EUR, while in 2019 the net result was slightly lower and amounted to 940 million EUR, or $28 \%$ of net economic performance. The recovery could be also observed in terms of the increased number of manufacturing companies, and other parameters related to this increase. In the five-year period from 2015 to 2019, the number of manufacturing companies increased by $5.1 \%$, the number of employees by $27.2 \%$, income by $17.9 \%$, net result by $35.4 \%$, GVA by $16.8 \%$, capital by $32.7 \%$, and the accumulated loss decreased by $-18.6 \%$, as well as total liabilities by $-1.7 \%$ (Republican Bureau of Statistics, 2020). 
In 2020, Serbian manufacturing sector faced a new challenge since it has been one of the most severely affected by the Covid-19 crisis. The intention of the Serbian government to strengthen the long-term position and status of manufacturing industry at the regional and European market, despite Covid-19 pandemic, was clearly stressed by the governmental authorities. After the initial shock and three months long lockdown in 2020 , all sectors, including manufacturing, have started to gradually reopen. Some companies recovered faster than others by adjusting their business operations to the new circumstances and have proved to be more resilient to the crisis than others. Although this depends of the companies' readiness to adapt, it is also highly related to the external environment including regulation changes and measures imposed by the state, together with the measures prescribed by the company itself.

The first part of this research was dedicated to explore the influence of Covid-19 crisis on various segments of manufacturing companies' businesses. Based on the results of this impact analysis and observed changes in the companies' business revenue and employees' structure and income variations, the effects of some kind of responses of the manufacturing companies to the Covid-19 crisis were assessed. The most common and widespread measures manufacturing companies have taken coping crisis were explored in order to determine the recommendations for survival, offensive business strategies and further development of manufacturing organizations, during and after the crisis.

The way in which companies fight and keep up with the Covid-19 crisis and its effects, largely depended on the state's attitude toward the crisis, state restrictions and support that companies had, as well as the security they felt doing business in Serbia in crisis situation. Serbian economy passed through the period of serious restrictions in international traveling and transfer of goods and cross-border trade, disruption of supply chains and other kind of limitations that endangered Serbian economy. Therefore, this study also explores the attitude of the manufacturing companies toward the state measures and their consistency, as well as expectations they had from the state institutions and authorities. It reveals state and sectorial capabilities and readiness to effectively manage the crisis, as well as the readiness of the manufacturing companies' employees and management to adapt to the new working environment caused by the Covid-19 pandemic, in order to lessen its impact on the companies' performance and profitability.

\section{LITERATURE REVIEW}

Since the emergence of Covid-19 in 2020, it has become one of the most commonly researched topics, capturing the attention of the scientists and researchers from various fields of study around the world. The impact of Covid-19 crisis on the economy was analyzed in the research done by Gourinchas 
(2020), while Lenoël \& Young (2021) set out a framework that can be used to evaluate policies intended to mitigate the economic effects of Covid-19. Nicola et al. (2020) summarized the socio-economic impact of Covid-19 pandemic, taking into account individual aspects of the world economy. The importance of open access, innovation, and knowledge management for combat and survival in crisis conditions was emphasized in the research of Chesbrough (2020). Kraus et al. (2020) confirmed the negative impact of crisis on business operations and results. Lee et al. (2020) investigated problems in cooperation with suppliers, changes in demand, and limited availability of human resources and financial capital, as basic factors that contribute to negative business trends in Covid-19 crisis conditions.

Many other authors and studies dealt with the economic recovery after Covid-19 pandemic. CarlssonSzlezak et al. (2020) explained that policy innovations could have an impact on economic recovery, like "bridge loans" or moratorium on mortgage payments. Sharma et al. (2021) developed a flexible economy model and discussed two policies that attempt to moderate the impact of crisis. This model can be accommodated to the wide range of situations.

Covid-19 pandemic has strongly influenced human capital, i.e. led to job losses, and a decrease in personal income of employees. The pandemic has led to the increased poverty and social stratification (Palomino et al., 2020; Brunori et al., 2020); when the most vulnerable population groups were affected much more than others (Fan et al., 2020). Béland et al. (2020) confirmed in their study that Covid-19 crisis has created the decline in number of employees, and the growth of unemployment rates. The pandemic crisis has led to a significant drop in productivity in small and medium-sized enterprises, which have reduced the number of employees in order to maintain their business (Nyanga \& Zirima, 2020). However, certain industries used unstable macroeconomic conditions and achieved high profits, so the crisis did not negatively affect salaries of their employees (Béland et al., 2020).

Many authors perceived the importance of government actions to support economic recovery. There is an opinion that governments today face a choice in a unique moment in history: to use it to build a stronger economy that is cleaner and more resilient, or further follow an old-fashioned economy driven by fossil-fuels and debt-laden consumption (Jung \& Murphy, 2020). Baldwin et al. (2020) and Magno \& Cassia (2021) stated that government support should be prompt and strong, preventing liquidity problems, and avoiding unnecessary losses. Nyanga \& Zirima (2020) agree that the state role in reducing the negative impact of Covid-19 crisis has to be significant. Kuckertz et al. (2020) confirmed that state role is of great importance as the first aid for small and medium-sized enterprises, at the beginning of crisis, in order to support their liquidity, which is primarily at risk. Following this first aid measures, state should implement further support measures for the development of small and medium- 
sized enterprises, and their survival in times of crisis. State aid support, combined with the crisis management at organizational level, enables survival and development of companies during Covid-19 pandemic (Islam et al. 2020). Alves et al. (2020) proposed crisis resilience model for small and mediumsized enterprises. They have defined five strategies for these organizations, for their survival and development in crisis conditions.

Similarly, as to the global level, Covid-19 crisis and possibilities for its mitigation were discussed by some authors giving the example of the Republic of Serbia. Negative impact of Covid-19 pandemic on Serbian enterprises was analyzed conducting online survey, targeting top and middle management. This study identified internal strengths and weaknesses, as well as external opportunities and threats on the Serbian companies' competitiveness during the pandemic (Adzic \& Al-Mansour, 2021). Savic et al. (2021) analyzed the competitiveness of the Serbian economy by using the Country Competitiveness Index, emphasizing the importance of microeconomic indicators to analyze crucial segments for the economy recovery. The sectorial studies about the Covid-19 pandemic in Serbia usually target the tourism sector or are dealing with behavioral aspects of stress provoked by Covid-19 pandemic. However, there were not many studies that consider fully or in some segments the impact of Covid-19 crisis on the manufacturing sector in Serbia.

Stojcic (2020) believes that a Covid-19 crisis affects all industries, which recorded revenue decrease, liquidity shortage, problems with customers and suppliers, after the outbreak of Covid-19 pandemic. Manufacturing industry was especially affected by the negative aspects of crisis (Xin et al., 2020), while the losses in the manufacturing industry have led to a decline in economic activity in many countries, therefore certain measures that should apply in the post-crisis period were examined (Sodhi, 2020). Harris et al. (2020) explored the manufacturing in Covid-19 recession and changes in manufacturing outputs by sector. It considered pre-Covid-19 conditions as well as various post-Covid-19 strategies, which lead to the conclusion that it would be difficult to follow either individual strategy. The solution could be found in business continuity plans, which should strengthen the resilience of companies and focus on their sustainability in crisis conditions (Islam et al., 2020). Cai \& Luo (2020) proposed two-step measures to be implemented in manufacturing industry, with their help it would be easier to get out of the crisis, and adapt to the new conditions in the post-crisis period.

\section{METHODOLOGY}

A questioner-based survey was conducted among manufacturing companies in the Republic of Serbia, referring to the period during April and May 2021. The research was performed more than a year since Covid-19 pandemic began. Manufacturing companies had enough time to estimate the impact of 
pandemic on certain segments of their business, and to apply appropriate measures, directed either to defense themselves from the negative effects of the crisis, or to use opportunities and chances in new macroeconomic business conditions. The research was conducted on a sample of 392 companies, 37 of which were from the manufacturing sector. The questionnaire contained questions that defined descriptive characteristics of the sample, and questions regarding applied measures for survival and sustainable business during Covid-19 pandemic. The questionnaire also contained questions related to the government role in crisis conditions, and the expected state measures for supporting the needs of manufacturing companies.

In accordance with the previous literature review, defining hypotheses is logically based on the expected results of the empirical research. In this sense, three hypotheses were defined, which assume the impact of Covid-19 pandemic on manufacturing companies, and importance of state measures in Covid-19 crisis conditions in the Republic of Serbia.

$H_{1}$. Covid-19 crisis has significantly affected revenue of the manufacturing companies, due to the specifics of their business

$\mathrm{H}_{2}$. Covid-19 crisis has not significantly affected the structure and income of employees in the manufacturing companies, due to State aid measures

$\mathrm{H}_{3}$. State aid measures have a significant role in sustaining business continuity and the development of the manufacturing companies in Covid-19 crisis

Standard statistical methods were used for the analysis of empirical data, descriptive statistics, Kolmogorov-Smirnov and Shapiro-Wilk normality tests, as well as non-parametric Wilcoxon Signed Ranks Test, for analysis of statistical significance of differences in arithmetic means.

\section{EMPIRICAL RESULTS}

The research sample was analyzed according to the business characteristics of manufacturing companies, as well as according to the demographic characteristics of entrepreneurs (company owners or managers). The research sample consisted of small and medium-sized enterprises, with the majority of small business organizations ( $59.5 \%$ according to the number of employees, and $64.9 \%$ according to the amount of operating income). Mostly mature manufacturing companies participated in the research. Almost $90 \%$ have been operating for 6 or more years (89.2\%), while $67.6 \%$ of the observed companies have been active for more than 10 years. According to empirical data, the amount of startup capital differs in research sample. $32.4 \%$ of respondents established their company with less than EUR 1,000 of startup capital, $29.7 \%$ started business activities with EUR 1,000-5,000, while $32.4 \%$ of companies had a higher start-up capital base (over EUR 5,000). More than half of organizations operate in 
international business $(56.8 \%)$, while majority of the observed sample don't have online sales (83.8\%). The research also analyzed the characteristics of entrepreneurs of manufacturing companies. According to the research results, owners and managers of the observed organizations are mostly male $(67.6 \%)$ and they are over 40 years old. $94.6 \%$ of entrepreneurs are over 40 , and the majority of respondents are in the age group "41-50 years" (56.8\%). When it comes to the educational structure of entrepreneurs, $40.5 \%$ have secondary education, $21.6 \%$ vocational, while $37.8 \%$ have the highest, university degree.

Empirical distribution, performed using Kolmogorov-Smirnov and Shapiro-Wilk normality tests, has shown that the empirical data significantly deviate from the normal distribution, which defined the choice of nonparametric tests for statistical analysis of obtained survey results.

After checking the distribution normality, the impact of Covid-19 crisis on revenue, structure and salary of employees in manufacturing companies was analyzed, as well as the pandemic influence on various segments of their businesses. Descriptive statistical analysis of Covid-19 impact on operating revenue, salary and number of employees, in the period 2019-2021, is specified in Table 1.

\section{TABLE 1. IMPACT OF COVID-19 ON REVENUE, STRUCTURE AND SALARY OF EMPLOYEES}

\begin{tabular}{lccc}
\hline Revenue change & Frequency & $\%$ & Cumulative $\%$ \\
\hline Decrease $>75 \%$ & 7 & 18.9 & 18.9 \\
Decrease $50 \%-75 \%$ & 7 & 18.9 & 37.8 \\
Decrease $25 \%-50 \%$ & 10 & 27.0 & 64.8 \\
Decrease $<25 \%$ & 7 & 18.9 & 83.7 \\
Without change & 5 & 13.5 & 97.2 \\
Increase $<25 \%$ & 0 & 0.0 & 97.2 \\
Increase $25 \%-50 \%$ & 1 & 2.8 & 100.0 \\
Total & 37 & 100.0 & \\
\hline Employee structure change & Frequency & $\%$ & Cumulative \% \\
\hline Decrease $\geq 10 \%$ & 4 & 10.8 & 10.8 \\
Decrease $11 \%-30 \%$ & 2 & 5.4 & 16.2 \\
Decrease 31\%-50\% & 1 & 2.7 & 18.9 \\
Decrease $\leq 51 \%$ & 2 & 5.4 & 24.3 \\
Without change & 28 & 75.7 & 100.0 \\
Total & 37 & 100.0 & \\
\hline Salary change & Frequency & $\%$ & Cumulative \% \\
\hline Decrease $\geq 10 \%$ & 2 & 5.4 & 5.4 \\
Decrease $11 \%-30 \%$ & 6 & 16.2 & 21.6 \\
Decrease 31\%-50\% & 2 & 5.4 & 27.0 \\
Decrease $\leq 51 \%$ & 2 & 5.4 & 32.4 \\
Without change & 25 & 67.6 & 100.0 \\
Total & 37 & 100.0 & \\
\hline
\end{tabular}

Source: Authors

Hypothesis $H_{1}$ stated that Covid-19 crisis has significantly affected revenue of the manufacturing companies, due to the specifics of their business. Based on the presented data (Table 1) $\mathrm{H}_{1}$ was confirmed, and it can be concluded that $83.7 \%$ of manufacturing companies operated with a reduced 
revenue volume, with $18.9 \%$ of companies affected by the reduction of more than $75 \%$. Operating revenues remained at the same level in $13.5 \%$ of companies, and only $2.8 \%$ of organizations confirmed that Covid-19 pandemic contributed to the increase in their revenues.

In Hypothesis $\mathrm{H}_{2}$, it was assumed that Covid-19 crisis has not significantly affected the structure and salary of employees in the manufacturing companies, which was confirmed by the Table 1 analysis. After the outbreak of Covid-19 pandemic, no significant change in the structure of employees in manufacturing companies was recorded (as confirmed by $75.7 \%$ of respondents). The majority of companies that reduced the number of employees (10.8\% of respondents), confirmed that reduction was up to $10 \%$ of total number. Larger reductions, more than $50 \%$ of employee number, were also noted (in $5.4 \%$ of organizations). As seen from the presented results, most manufacturing companies did not reduce the salaries of their employees, as confirmed by $67.6 \%$ of respondents. In most cases, a reduction of up to $30 \%$ was recorded (cumulatively in $21.6 \%$ of companies). Significant reductions of salaries, $51 \%$ or more, were conducted in $5.4 \%$ of manufacturing companies.

In hypothesis $\mathrm{H}_{2}$ it was also presumed that structure and salary of employees in the manufacturing companies wasn't significantly affected due to State aid measures. Considering that manufacturing companies had a decline in business revenues in period 2019-2021, and that there was no significant change in the structure and salaries of employees, it can be concluded that this was influenced by state support measures. State measures in Republic of Serbia were aimed at improving liquidity and preserving jobs, they were implemented during 2020, immediately after the outbreak of the Covid-19 pandemic, and they continued in 2021 (Marinovic Matovic \& Vemic Djurkovic, 2021). These findings also confirmed hypothesis $\mathrm{H}_{2}$.

Impact of Covid-19 pandemic on other business segments was analyzed by non-parametric Wilcoxon Signed Ranks Test. The results are provided in Table 2.

TABLE 2. IMPACT OF COVID-19 ON OPERATIONAL ACTIVITIES

\begin{tabular}{lccc}
\hline & $\mathbf{Z}$ & $\begin{array}{c}\text { Asymp. Sig. } \\
\text { (2-tailed) }\end{array}$ & $\begin{array}{c}\text { Exact Sig. } \\
\text { (2-tailed) }\end{array}$ \\
\hline Median - Employee health issues & -3.824 & .000 & $/$ \\
Median - Business interruption & -809 & .421 & 1 \\
Median - Organizational difficulties & -.527 & .590 & 1 \\
Median - Payment delays & -.527 & .590 & 1 \\
Median - Delivery problems & -1.241 & .217 & $.538^{b}$ \\
Median - Increased costs & 1 & 1 & 1 \\
Median - Working hours change & -1.544 & .135 & 1 \\
Median - Business change & -.171 & .859 & 1 \\
Median - Absence of employees & -2.648 & .006 & 1 \\
Median - Alternative way of doing business & -2.379 & .009 & $.149 \mathrm{~b}$ \\
Median - Difficult access to capital & -2.081 & .032 & \\
Median - Difficult fulfillment of contractual obligations & -.538 & .596 & \\
Median - Difficult access to business information & 1 & &
\end{tabular}


BUSINESS REVENUE AND JOB RETENTION DURING COVID-19 CRISIS IN MANUFACTURING SECTOR IN SERBIA

\begin{tabular}{clll}
\hline Median - Other & $/$ & $/$ & $.451^{\mathrm{b}}$ \\
\hline a. & Sign test & & \\
b. & Binomial distribution used & &
\end{tabular}

Source: Authors

Hypothesis $H_{1}$ posted that manufacturing companies' revenue was significantly affected due to the specifics of their business. Using the non-parametric Wilcoxon Signed Ranks Test, the estimated impact of Covid-19 crisis on certain business segments was analysed, that is whether it differs significantly from the median value (value 3). The findings presented in Table 2 further validate hypotheses $H_{1}$. Significant impact of Covid-19 pandemic has been confirmed in several business segments: health of employees (sig. 2-tailed 0.000); absence of employees (sig. 2-tailed 0.006); implementation of alternative business models (sig. 2-tailed 0.009); and difficult access to capital (sig. 2-tailed 0.032). Covid-19 pandemic had no significant impact on business interruptions (sig. 2-tailed 0.421), on organization (sig. 2-tailed 0.590), payment settling (sig. 2- tailed 0.590), delivery schedule (sig. 2-tailed 0.217 ), operating costs (sig. 2-tailed 0.538), business hours (sig. 2-tailed 0.135 ) or business operations (sig. 2-tailed 0.859). Unexpected crisis didn't have significant impact on contract obligations (sig. 2tailed 0.596), and on information flow (sig. 2-tailed 0.149), as indicated in the Table 2.

Furthermore, the research also analyzed the measures applied by manufacturing companies after the pandemic outbreak, which helped them to survive and sustain their business growth in unpredictable macroeconomic conditions. Results are shown in Figure 1.

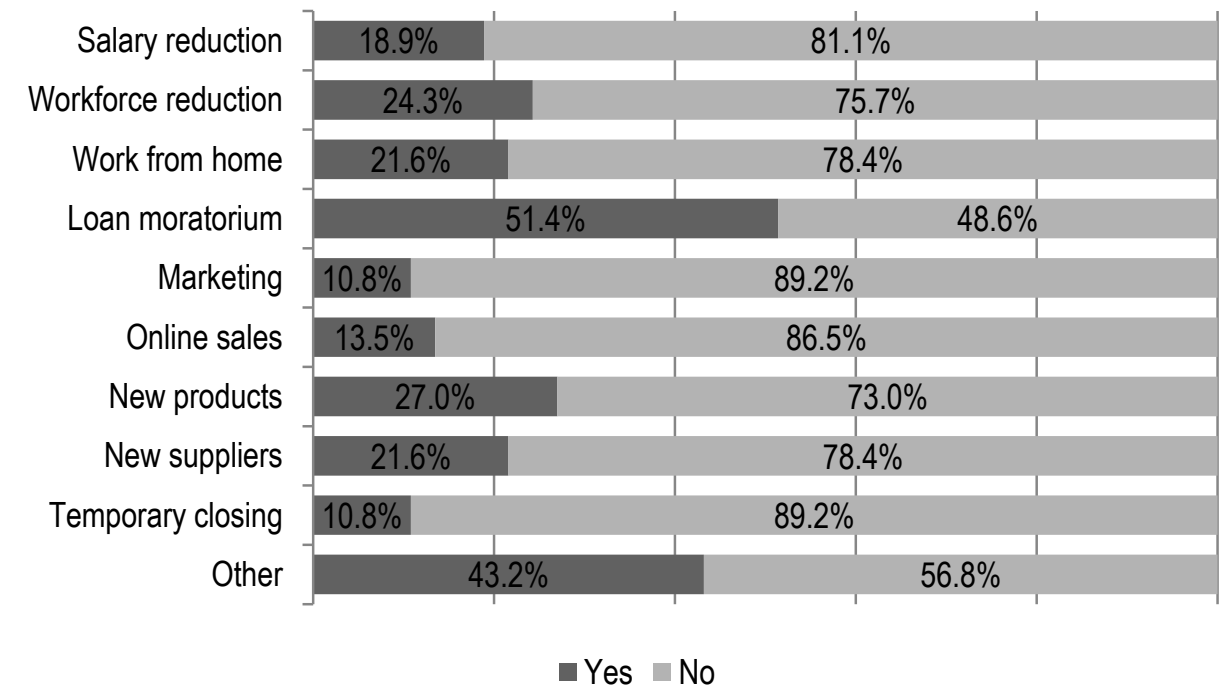

FIGURE 1. ANTI-COVID MEASURES APPLIED IN MANUFACTURING COMPANIES

Source: Authors 
The most common measure that manufacturing companies have applied to protect and develop their business was moratorium (Figure 1). Loan moratorium was offered by commercial banks, for deferral of loan obligations, and $51.4 \%$ of the observed companies used this opportunity. $27.0 \%$ of manufacturing companies introduced adjusted or new products after the outbreak of Covid-19 crisis, while $21.6 \%$ partially introduced work from home for their employees. The same share of respondents $(21.6 \%)$ started cooperation with new suppliers in order to preserve their business continuity. New marketing measures were applied by $10.8 \%$ of manufacturing companies, while some other unmentioned specific activities were applied in $43.2 \%$ of the observed organizations.

Hypothesis $\mathrm{H}_{3}$ assumed that State aid measures have a significant role in sustaining business continuity and the development of the manufacturing companies in Covid-19 crisis. Hypothesis testing was performed by analysis of manufacturing companies' attitudes toward the state role in crisis conditions. Hypothesis $\mathrm{H}_{3}$ was confirmed by research results presented in Table 3.

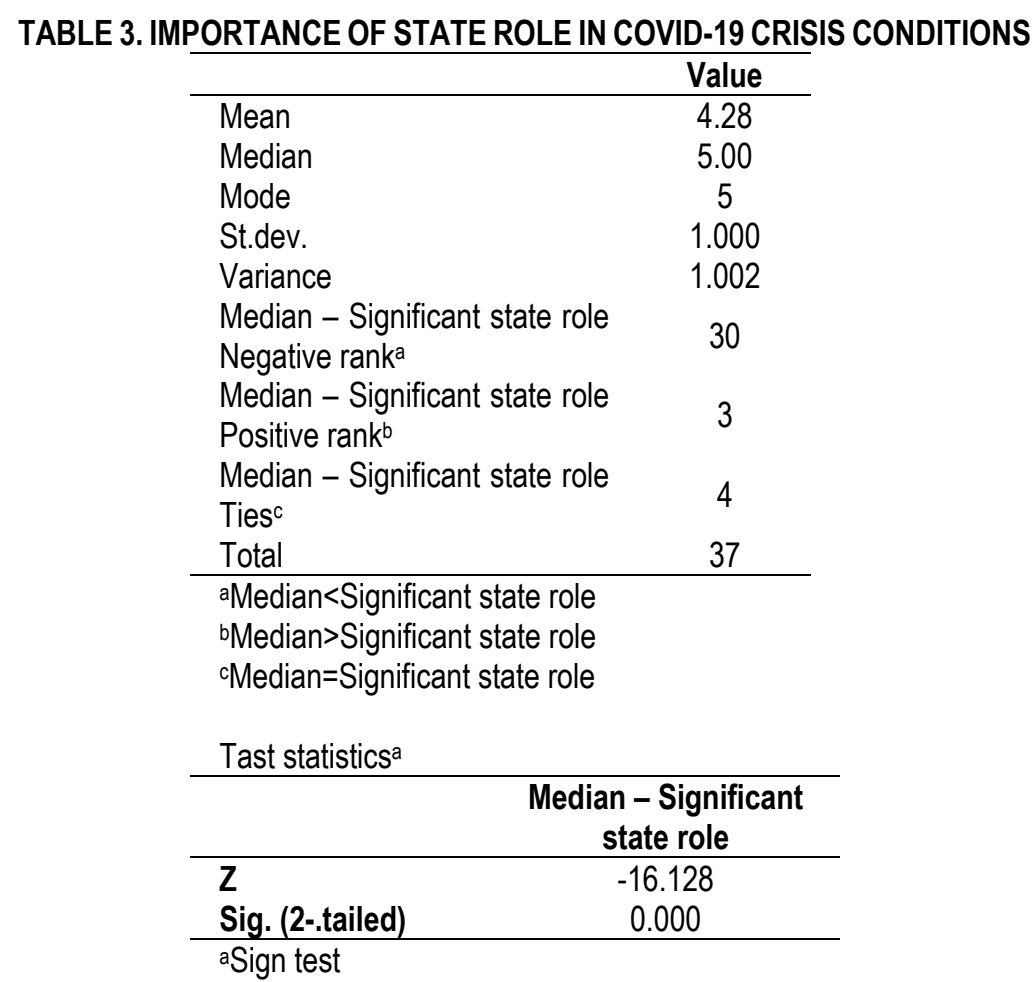

Source: Authors

According to the obtained results, it can be concluded that most manufacturing companies fully agree with the statement that the state should play a significant role in mitigation of consequences of Covid-19 crisis. Based on Wilcoxon Signed Ranks test, 30 negative ranks were confirmed, which means that 30 companies rated (with a grade higher than 3 ) the need for a significant state role in mitigating crisis 
consequences ( $81 \%$ of the observed sample). Based on Wilcoxon Signed Ranks test ( $Z=-16.128$; Sig. $=0,000$ ), it can be concluded that the average value is significantly higher than the median value. The research results confirmed hypothesis $\mathrm{H}_{3}$, that the state role in sustaining business continuity and the development of the manufacturing companies in Covid-19 crisis is significant.

Manufacturing companies' expectations, regarding the future state aid measures, were also analyzed, and the results are presented in Figure 2.

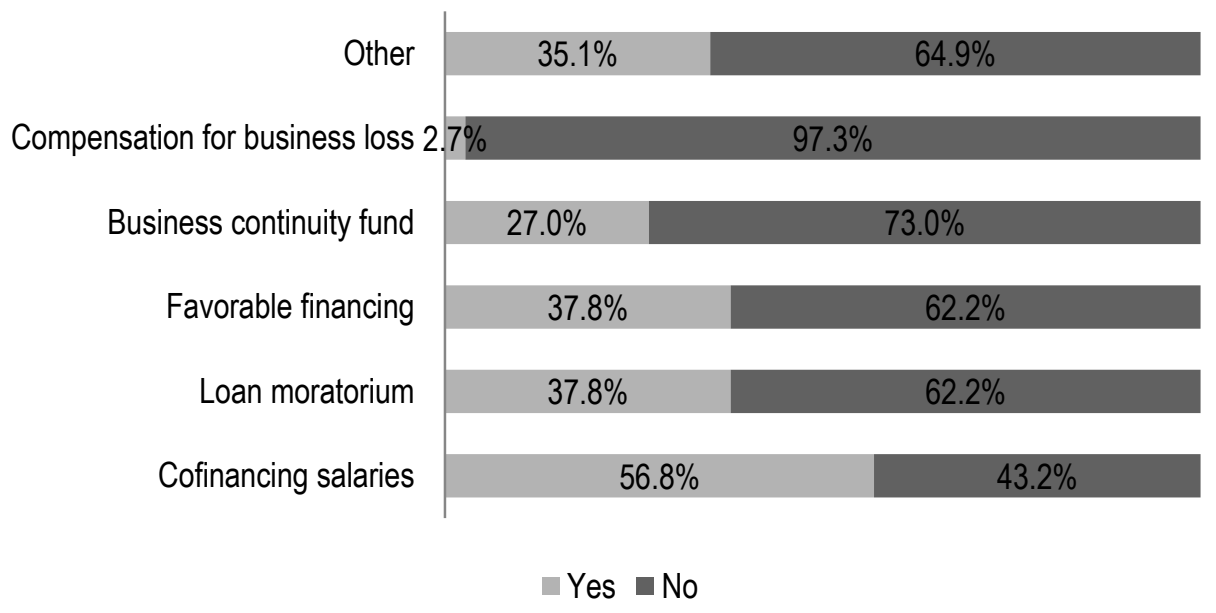

FIGURE 2. EXPECTED ANTI-COVID STATE MEASURES

Source: Authors

The results indicate that manufacturing companies expect the prolongation of state measures directed towards co-financing of salaries for their employees, as confirmed by $56.8 \%$ of respondents. This is a measure that has already been implemented by the state, after the outbreak of Covid-19 pandemic, and it is desirable in the following period as well. Manufacturing organizations do not expect a loan moratorium $(62.2 \%)$, even though this measure was the most commonly used after the pandemic outbreak. Regarding the introduction of new favorable financing, $62.2 \%$ of respondents do not consider this measure necessary. $73.0 \%$ of companies do not even want business continuity grants from the state, and $97.3 \%$ of respondents do not expect from the state to compensate their business loss.

\section{DISCUSSION}

This study investigated the impact of Covid-19 on the manufacturing companies' business revenue, their employees, and subsequently influence of crisis on various segments of their business. It also analyzed the most common measures applied by manufacturing companies after the pandemic 
outbreak, significance of state aid measures, and manufacturing companies' expectations, regarding the future state support.

The research study has three significant findings. First, it confirms that Covid-19 crisis has statistically significant impact on revenue of the manufacturing companies, due to the specifics of their business. These results are supported by previous studies, which implied the manufacturing sector as the most affected by Covid-19 pandemic (Xin et al., 2020; Stojcic, 2020, Marinovic Matovic \& Lazarevic, 2020). Previous research studies also found that certain business aspects are factors with negatively impact on company operations and revenue, such as difficult access to financial capital, insufficient human capital, and changes in demand that cannot be met by rapid business adaptation (Kraus et al., 2020; Lee et al., 2020). Our results supported these findings, and confirmed that Covid-19 pandemic had significant impact on several business segments (employee health and absence, lack of capital, and new business models); which led to a decrease in operating revenue.

Second, the results obtained in empirical research confirmed that Covid-19 crisis doesn't have statistically significant impact on the structure and salary of employees in the manufacturing companies. These results are not consistent with some previous studies, which suggested that Covid-19 crisis has strongly influenced the number of employees in most sectors and increased the unemployment rate (Béland et al., 2020; Nyanga \& Zirima, 2020), where the most vulnerable employee categories were most affected (Fana et al., 2020). According to the research results, employee salaries in manufacturing companies are not significantly affected by Covid-19 pandemic. However, other research confirmed that the crisis has caused inequality and poverty among certain categories of employees (Palomino et al., 2020; Brunori et al., 2020). Our results are in line with Béland et al. (2020) study, who found that Covid19 has no significant impacts on salaries, whereby certain sectors also recorded growth during crisis. According to research results, state aid measures are essential for preserving the salaries and structure of employees in manufacturing companies, when a decline in business revenues in period 2019-2021 is considered, and the fact that several business segments were significantly affected by Covid-19 crisis.

Third research result confirmed a significant role of state measures for survival and maintaining business continuity of the manufacturing companies in Covid-19 crisis conditions. Similarly, with present study, Kuckertz et al. (2020) confirmed importance of state role for liquidity support, especially at the beginning of a pandemic. Nyanga \& Zirima (2020) agree, however they point out that support measures are most effective if applied together with crisis management measures in the company. Baldwin et al. (2020) and Jung \& Murphy (2020) also concluded that state role is important, especially for the prevention of liquidity risks and business losses. These findings are in line with the present research results conducted in the Republic of Serbia. 


\section{CONCLUSIONS}

This paper confirmed that the Covid-19 crisis has substantial impact on business revenue of manufacturing companies, and on several operational segments, primarily the capacity of human capital, which was limited due to endangered employee health and their frequent absence, and difficult access to financial capital. In difficult macroeconomic conditions, manufacturing companies maintained their business continuity by applying certain measures. These were anti-Covid defense measures, taken by manufacturing companies in a crisis environment, as well as state aid measures for preserving and increasing liquidity. According to the research results, state support measures have significant role for survival and business continuity of the manufacturing companies in Covid-19 crisis conditions. With the support of the appropriate state measures, Covid-19 crisis didn't significantly affect structure and earnings of employees, as confirmed in the research study.

Maintening business continuity and profitability in the crisis conditions implies the application of various measures, specific to each company. This implies the introduction or strengthening of crisis management, through strategic and operational planning, human resource management, optimization of business processes and decision-making, all the way to early identification of crisis, and developing an adequate concept for maintaining business continuity.

Not many companies in Serbia had previously developed business continuity plans and their readiness to respond to the external environmental changes was at very low level. The application of already developed methodologies to prepare disaster recovery plans and to maintain the business continuity would be very useful, such as implementation of the ISO standards (ISO 22301:2019 Security and resilience - Business continuity management system) or other good practice guidelines presented by various corporations, communities and associations.

The creation of the business continuity plans is a complex process that usually involves some major steps: risk assessment and business impact assessment, development of the business continuity strategy and finally well-developed business continuity plan, including assigned resources, roles and responsibilities for all stakeholders in the continuity management system.

Regarding the state role, the research results imply that state support should be directed towards developing business and improving the resilience of manufacturing companies on future global, national or regional crises. Specific state measures should be adapted at the local level and according to the specifics of the sector. Adequate state support measures should provide a quick response to crisis, appropriate financial support for companies, directed towards the creation of conditions for further progress, growth and development in new circumstances.

Study limitations exist due to a constrained research scope, since survey was conducted in only one country, Republic of Serbia, and only in manufacturing companies. The research was performed with a 
small sample size, which is another limiting factor. Study also faced another restriction, in the form of difficult access to respondents, due to restricted movements and physical distance in Covid-19 crisis conditions. Research faced another limitation, a relative objectivity of respondents, which is common when data collection is based on a survey questionnaire, i.e. based on subjective evaluation of respondents.

A recommendation for future research is to overcome all the above limitations. At the same time, future research should encompass the same group of manufacturing companies, and monitor the effects of the applied measures to mitigate the damages caused by Covid-19 crisis. Also, the influence of Covid19 crisis on the selected business segments of manufacturing organizations should be monitored in the three-year period and the comparison would reveal companies' readiness to respond to the changes in the business environment.

\section{REFERENCES}

Adzic, S. \& Al-Mansour, J. (2021). The Negative Impact of Covid-19 on Firms: Insights from Serbia. Eastern European Economics, 59, 5, 472-486.

Alves, J.C., Lok, T.C., Luo, Y.B. \& Hao, W. (2020). Crisis Management for Small Business during the COVID-19 Outbreak: Survival, Resilience and Renewal Strategies of Firms in Macau, ResearchSquare, https://doi.org/10.21203/rs.3.rs34541/v1.

Baldwin, R. (2020). Keeping the lights on: Economic medicine for a medical shock. VoxEU.Org, 13 March. Retrieved from https://voxeu.org/article/how-should-we-think-about-containing-covid19-economic-crisis

Béland, L.P., Brodeur, A. \& Wright, T. (2020). The short-term economic consequences of COVID-19: exposure to disease, remote work and government response. IZA Discussion Paper Series, 13159.

Brunori, P., Maitino, M.L., Ravagli, L. \& Sciclone, N. (2020). Distant and unequal. Lockdown and inequalities in Italy. Working Papers - Economics, wp2020_13.rdf, Universita' degli Studi di Firenze, Dipartimento di Scienze per l'Economia e l'Impresa.

Cai, M. \& Luo, J. (2020). Influence of COVID-19 on Manufacturing Industry and Corresponding Countermeasures from Supply Chain Perspective. Journal of Shanghai Jiaotong University (Science), 25, 409-416.

Carlsson-Szlezak, P., Reeves, M. \& Swartz, P. (2020). Understanding the Economic Shock of Coronavirus. Harvard Business Review, 27 March. Retrieved from https://hbr.org/2020/03/understanding-the-economic-shock-of-coronavirus

Chesbrough, H. (2020). To recover faster from Covid-19, open up: managerial implications from an open innovation perspective. Industrial Marketing Management, 88, July, 410-413.

China-CEE Institute. (2019). Industry overview in Serbia and its contribution to economy growth, exports and employment. Weekly briefing, 19, 2, 1-6.

Dingel, J.I. \& Neiman, B. (2020). How Many Jobs Can be Done at Home? Chicago: Brecker Friedman Institute. 
Fana, M., Perez, S.T. \& Fernandez-Macias, E. (2020). Employment impact of Covid-19 crisis: from short term effects to long terms prospects. Journal of Industrial and Business Economics, 47, $391-$ 410.

Gourinchas, P.O. (2020). Flattening the pandemic and recession curves. In R. Baldwin \& B. Weder di Mauro (Eds.), Mitigating the COVID Economic Crisis: Act Fast and Do Whatever It Takes (pp. 31-39). CEPR Press VoxEU.org eBook.

Harris, J.L., Sunley, P., Evenhuis, E., Martin, R., Pike, A. \& Harris, R. (2020). The Covid-19 crisis and manufacturing: How should national and local industrial strategies respond? Local Economy: The Journal of the Local Economy Policy Unit, 35, 4, 403-415.

Islam, A., Mansoor, A., Rahman, M., \& Abd Wahab, S. (2020). Adjusting a strategic cash-flow model for Bangladeshi small and medium enterprises: The art of surviving Covid-19 emergency. Business Excellence and Management, 10 (Special issue 1), 194-213.

Jung, C. \& Murphy, L. (2020). Transforming the economy after Covid-19 - A clean, fair, and resilient recovery. London: Institute for Public Policy Research.

Kraus, S., Clauss, T., Breier, M., Gast, J., Zardini, A. \& Tiberius, V. (2020). The economics of COVID19: Initial empirical evidence on how family firms in five European countries cope with the corona crisis. International Journal of Entrepreneurial Behaviour \& Research, 26, 5, 10671092.

Kuckertz, A., Brändle, L., Gaudig, A., Hinderer, S., Reyes, C.A.M., Prochotta, A. \& Berger, E.S. (2020). Startups in times of crisis - A rapid response to the COVID-19 pandemic. Journal of Business Venturing Insights, 13, C, e00169.

Lee, C.K., Song, H.J., Bendle, L.J., Kim, M.J. \& Han, H. (2012). The Impact of NonPharmaceutical Interventions for 2009 H1N1 Influenza on Travel Intentions: A Model of GoalDirected Behavior. Tourism Management, 33, 1, 89-99.

Lenoël, C. \& Young, G. (2021). Modelling the impact of Covid-19 on the UK economy: an application of a disaggregated New-Keynesian model. NIESR Discussion Paper No. 531, 1-43.

Magno, F. \& Cassia, F. (2021). Firms' responses to the COVID-19 crisis in the tourism industry: effects on customer loyalty and economic performance. An International Journal of Tourism and Hospitality Research, Anatolia, DOI: 10.1080/13032917.2021.1916551

Marinovic Matovic, I. \& Lazarevic, A. (2020). Covid-19 Crisis Management in Manufacturing Industry Organizations in the Republic of Serbia. Proceedings of The Fifth International Conference MASING 2020, MECHANICAL ENGINEERING IN XXI CENTURY, Nis, December 09-10, pp.403-406.

Marinovic Matovic, I. \& Vemic Djurkovic, J. (2021). Covid-19 impact on trade and production organizations: The effects of governmental measures in the state of emergency. Thematic Collection of Papers of International Significance - Psychology of disaster, state of emergency and their effects on health, Faculty of Philosophy, Kosovska Mitrovica, pp.135-151.

Nicola, M., Alsafi, Z., Sohrabi, C., Kerwan, A., Al-Jabir, A., losifidis, C., Agha, M. \& Agha, R. (2020). The socio-economic implications of the coronavirus pandemic (COVID-19): A review. International Journal of Surgery, 78, June 2020, 185-193.

Nyanga, T. \& Zirima, H. (2020). Reactions of small to medium enterprises in Masvingo, Zimbabwe to Covid-19: Implications on productivity. Business Excellence and Management, 10 (Special issue 1), $22-32$. 
Palomino, J.C., Rodríguez, J.G. \& Sebastián, R. (2020). Wage inequality and poverty effects of lockdown and social distancing in Europe. INET Oxford Working Paper (No. 2020-13).

Republican Bureau of Statistics. (2020). TRENDS Business performance of the economy of the Republic of Serbia, 2015-2019. Retrieved from https://publikacije.stat.gov.rs/G2020/Pdf/G20208003.pdf

Savic, LJ., Boskovic, G. \& Micic, V. (2015). Structural Changes in Manufacturing Industry at Division Level - Serbia and New EU Member States. Industrija, 43, 4, 25-45.

Savic, N., Lazarevic, J., Vjetrov, A. \& Marinkovic, E. (2021). Serbian economy recovery in the post Covid-19 era: cluster approach. Journal of business economics and management, 69, 3-4, 243-259.

Segal, E., 2021. How Remote Working During Covid Is Changing Crisis Management. Forbes, Washington, 4 Apr. Retrieved from https://www.forbes.com/sites/edwardsegal/2021/04/11/remote-working-during-covid-ischanging-crisis-management/?sh=26a29bc17dcd

Sharma, D., Bouchaud, J.P., Gualdi, S., Tarzia, M. \& Zamponi, F. (2021). V-, U-, L- or W-shaped economic recovery after Covid-19: Insights from an Agent Based Model. Plos one, 16, 3, e0247823.

Sodhi, H.S. (2020). Effect of Corona Virus on the Manufacturing and Supply Chain Industry across World. Industrial Engineering Journal, 13, 2504.

Stojcic, N. (2020). The impact of Covid-19 pandemic on the export competitiveness of manufacturing firms in Croatia. Economic Thought and Practice, 20, 2, 347-365.

Xin, G., Shan, Y., Weiqiang, Z. \& Yewei, T. (2020). How Do Firms Respond to Covid-19?: First Evidence from Suzhou, China. Emerging Markets Finance and Trade, 56, 10, 2181-2197. 